\title{
WELCOME TO THE FINAL ISSUE OF THE JOURNAL FOR 2021
}

\author{
Dr. Neale Fong FCHSM
}

President of Australasian College of Health Service Management

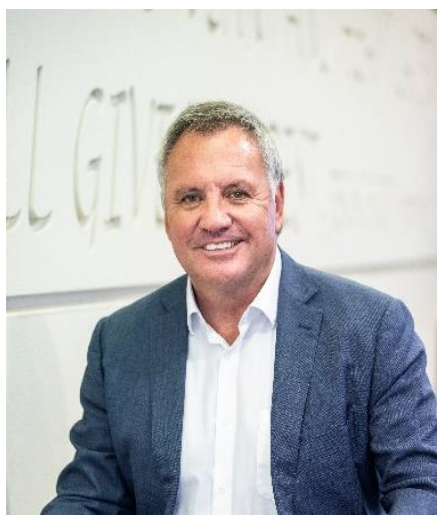

It has been another extraordinary year for the health system and its leaders across the globe as the pandemic wrought unplanned and unplotted transformation. It seems apparent that the pace of change is with us to stay and casting forward in 2022, we can expect more challenges as we grapple with some of the unknowns of living with Covid.

As health leaders, managers and executives, we are extremely aware that we step forward to "living with COVID" with an exhausted workforce, a potential tsunami of demand on our own mental health care capabilities, and indeed the demand from all those previously usual activities that have been left untended in the past two years. It is in these times that we must lead with compassion - the need for empathic, caring leadership has never been greater. I hope, too, that we understand that we are not alone and that it is the support of our peers that will make this journey forward a little bit easier.

A key aim of the College is to equip, empower and encourage our members not just when times are good but even more so when times are tough. In 2022 we will focus on creating networks that support members, wherever they are, through connection and comradery. It is our hope that you choose to reach out to your peers to support and be supported, as together we are better and stronger.

While it is important to support others and lead with compassion, we must do so by also taking care of ourselves. I ask each of you to ponder over the coming seasonal festivities and end of year celebrations just what you need to take care of yourself and know that in taking action to do so, ensure you have the resources to take care of your teams.

I would like to take this opportunity to thank Dr David Briggs $\mathrm{AO}$ for his steady and committed leadership of the College's Journal over many, many years. In doing so he has given back so much to the health sector in which he has worked for many decades. Thank you, David.

\section{Dr. Neale Fong FCHSM}

President of Australasian College of Health Service Management 